\title{
SUBLIME BELLEZA. APORTACIONES PARA UN SÍNTESIS CATEGORIAL (A PARTIR DE LA ESTÉTICA DE FRIEDRICH SCHILLER)
}

\author{
SUBLIME BEAUTY. CONTRIBUTIONS FOR A \\ SYNTHESIS OF CATEGORIES (FROM THE \\ AESTHETICS OF FRIEDRICH SCHILLER)
}

\author{
InMaCUlada Murcia SERrano* \\ Universidad de Sevilla
}

\begin{abstract}
RESUMEN: Lo bello y lo sublime constituyen categorías estéticas de diferente significación, especialmente, a partir de que Immanuel Kant las divorciara en la Crítica del juicio. Aunque Friedrich Schiller dedicó también textos distintos a cada una de ellas, en su caso es posible desentrañar las raíces comunes y los paralelismos estructurales que ostentan estos dos conceptos históricos. De ello puede surgir una propuesta de sintetización que deshaga los estériles compartimentos estancos en que a veces ha degenerado la estética.

Palabras Clave: Lo bello, lo sublime, Immanuel Kant, Friedrich Schiller, lo trágico, lo patético

ABSTRACT: The beautiful and the sublime are aesthetic categories of varying meaning, especially from their «divorce» in the Kantian Critique of Judgment. Although Friedrich Schiller also devoted several articles to each, it is possible to decipher the common roots and the structural parallels that these two historical concepts hold. In both Kallias and On the Aesthetic Education of Man, as well as On the sublime or On the pathetic, more or less explicit identification keys that point to a semantic contiguity of the beautiful and the sublime can be found. An alternative theory that undoes the sterile compartments into which aesthetics sometimes degenerates could emerge from here.
\end{abstract}

KEYWORDS: The beautiful, the sublime, Immanuel Kant, Friedrich Schiller, the tragic, the pathetic

* Departamento de Estética e Historia de la Filosofía de la Facultad de Filosofía de la Universidad de Sevilla. C/ Camilo José Cela s/n, 41018, Sevilla.imurcia@us.es. 


\section{Introducción}

La Crítica del juicio es, como se sabe, uno de los textos fundacionales de la estética moderna y, en cualquier caso, un referente insoslayable para todo el que quiera acercarse a los conceptos de lo bello y lo sublime ${ }^{1}$, los más importantes del marco categorial estético. En esa obra, ambos términos quedan divorciados y categorizados de forma independiente, en virtud de que cada uno activa una relación distinta entre las facultades humanas. Si en lo bello, la imaginación y el entendimiento juegan en libre movimiento acomodándose a la experiencia y provocando placer, en lo sublime, las facultades superiores entran en conflicto. $\mathrm{Y}$ ese conflicto provoca, en un primer momento, un sentimiento de displacer que, no obstante, termina siendo superado: «El sentimiento de lo sublime es, pues, un sentimiento de dolor que nace de la inadecuación de la imaginación, en la apreciación estética de las magnitudes, con la apreciación mediante la razón» (Kant 1999, 200). La tesis kantiana invita así a distinguir lo bello de lo sublime $e^{2}$ aunque el filósofo de Königsberg sólo es un caso más, tal vez sintetizador, de

\footnotetext{
${ }^{1}$ La palabra griega que alude a lo sublime es hýpsos; y, en alemán, erbaben (sustantivizado por J. J. Winckelmann). Según ha explicado Baldine Saint Girons, el griego hypsos es un sustantivo neutro perteneciente a una familia de términos, ligados todos al adverbio bypsi, que puede traducirse como «en alto». Por lo general designa la altura concebida como una dimensión espacial, opuesta a la anchura y a la longitud, y que, sucesivamente, asume el sentido de lo más alto, de cima o de culmen. La componente metafórica en griego resulta, pues, esencial. En cuanto al término latino sublimis, tiene su origen en la preposición sub, «bajo», «cerca» y en el adjetivo limis (limus), «oblicuo, «de través», o también, aunque menos consistente, en la preposición sub y el sustantivo limen, límite, «umbral». Sin embargo, en latín, la preposición sub designa no sólo una relación de inferioridad, de proximidad o de sumisión, sino también una desplazamiento de abajo hacia arriba y está relacionada con la preposición super, «sobre», del mismo modo que en griego la preposición bypo, «bajo», está relacionada con la preposición hyper, «sobre» (Saint Girons 2008, 91).

${ }^{2}$ Y no es el único. Richar Rorty, por ejemplo, planteó no hace muchos años que la búsqueda de lo bello es un intento de ordenar las cosas mejor conocidas de forma que se integren en modelos de organización más abarcadores y armoniosos. Ponía como ejemplos las demostraciones matemáticas elegantes o las explicaciones científicas. Se retrotraía al contraste platónico entre dianoia y noesis, en los que creía ver reflejados lo bello y lo sublime respectivamente. Para él, la búqueda de lo sublime sería un intento de llegar a establecer contacto con algo que no nos es familiar, porque es inefable. La línea que divide lo bello de lo sublime coincidiría aproximadamente con la que existe entre lo discursivo y lo relacionado con la inspiración; entre lo literal y lo metafórico; entre la participación en los hábitos sociales cuyas normas uno comprende, y las invitaciones para dejar de un lado esos hábitos $(2001,3)$. Actualmente, otros estudiosos defienden alguna forma de sintetización. Para José Luis Molinuevo, por ejemplo, lo sublime sería una culminación de lo bello «por contaminación» $(1998,144)$.
} 
una larga lista de autores que, olvidando al Pseudo Longino - quien no oponía bypsos a kalos — separaron los términos hasta hacerlos incompatibles. Rorty cita como antecedentes de la dicotomía kantiana a Addison y a Burke $(2001,4)$. Pero, ¿hemos de contentarnos con esa distinción? ¿No podemos pensar que, en ciertos aspectos, lo bello es lo mismo que lo sublime?

Uno de los autores que pueden ayudar a contestar esta preguta es precisamente un discípulo de Kant, el poeta, ensayista y dramaturgo, Friedrich Schiller, que dedicó varios textos a estas dos categorías estéticas. En concreto, las definiciones schillerianas de lo bello se encuentran en Kallias (1793) y en Las cartas sobre la educación estética del hombre (1795); ambos están compuestos de diversas cartas que Schiller envió a Christian Gottfried Körner, en el primer caso, y al Príncipe Augustenburg, en el segundo. El grueso de la reflexión schilleriana sobre lo sublime se halla, por su parte, en De lo sublime (1793) y en Sobre lo patético, su continuación; también cabe mencionar Sobre lo sublime (1801), que se publicó por primera vez en los Kleinere prosaische Schriften ${ }^{3}$. En todos los casos, la influencia de Kant es más que notoria.

Hay que tener en cuenta que, aún convaleciente de una grave enfermedad pulmonar, que terminaría arrebatándole la vida, en los últimos meses de 1792, Schiller decide estudiar la filosofía kantiana. De su estética tomará no pocos motivos, aunque mantenga, en algunos aspectos, sus reservas. El dramaturgo alemán admitió, por ejemplo, la tesis de que lo bello place sin concepto y, sobre todo, la centralidad de la razón práctica o del principio de autodeterminación de la voluntad. Pero rechazó el subjetivismo estético kantiano o el llamado carácter racional-subjetivo de la belleza, en tanto que hacía descansar la universalidad del juicio de gusto en lo puramente individual. En contraposición, Schiller intentará establecer una definición sensible-objetiva de la belleza en la que tengan cabida tanto su carácter sensible como sus aspiraciones a la objetividad. En lo que respecta al concepto de lo sublime, Schiller también tomó de Kant algunos instrumentos teóricos, si bien su propósito fue sobre todo extender el concepto kantiano a la explicación del pathos trágico y elaborar así una justificación filo-

\footnotetext{
${ }^{3}$ Dado que lo que nos interesa aquí es el análisis schilleriano de las categorías de lo bello y lo sublime en su generalidad y abstracción, dejamos a un lado el complemento hermenéutico que supondría el estudio de Sobre poesía ingenua y sentimental, mucho más circunscrita a la práctica concreta de la poesía o la literatura.
} 
sófica de la tragedia, el arte que con tanto esmero practicó (Oncina y Ramos 2006, 97).

La pregunta que queremos contestar aquí, basándonos en estos textos de Schiller, es si es posible establecer alguna correspondencia entre lo bello y lo sublime.

\section{Lo bello en Kallias}

Como ya hemos mencionado, la discusión schilleriana sobre el concepto kantiano de la belleza se encuentra, en parte, en la correspondencia que el pensador mantuvo con Christian Gottfried Körner a partir de diciembre de 1792. En esas cartas, que conocemos como Kallias, Schiller defendía que la belleza no podía hallarse en el campo de la razón teórica, ya que, como Kant había establecido, era independiente de los conceptos; sin embargo, sí podía encontrarse en el ámbito de la razón práctica, habida cuenta de la afinidad que para él existía entre belleza y libertad.

En la Crítica del juicio, Kant había explicitado que la belleza era el símbolo de la moralidad, lo cual no implicaba un repliegue de lo estético hacia lo moral, que hubiera dañado la autonomía del sentimiento, sino una sugerencia de analogías entre esas dos esferas del ser humano. La relación no podía radicar más que en la analogía, porque la libertad, en la filosofía crítica, no era susceptible de representarse en la intuición, y porque actuaba además como vehículo de penetración del hombre en el ámbito suprasensible. A la hora de vincular belleza y moralidad sin recurrir a esta analogía - innecesaria para quien cree que la libertad puede fenomenizarse_- Schiller introdujo en su definición de lo bello el matiz de que la libertad estética no era de hecho, sino en apariencia. Si un objeto sensible se nos presentaba eximido, aparentemente, de determinaciones materiales o finales, podía ser considerado como un producto de la autodeterminación. Aparentemente no quiere decir que el objeto tuviera que carecer de regla o de finalidad ${ }^{4}$, sino que, a la hora de apreciar su belleza, se debía hacer abstracción de esas deter-

\footnotetext{
${ }^{4}$ Algo que, en cualquier caso, era imposible: «Pero no existe ningún objeto en la naturaleza ni en el arte que podamos considerar libre de finalidad y de reglas, ni determinado por sí mismo» (Schiller 1990, 25).
} 
minaciones y prestar únicamente atención a su modo de aparecer. De hecho, seguramente por su condición de dramaturgo y poeta, Schiller era de la opinión de que todo objeto artístico debía estar, necesariamente, sometido a las reglas y a la técnica, pero debía aparecérsenos libre de ellas $(1990,25)^{5}$. Su belleza había de aflorar sin requerir del entendimiento ninguna explicación: «Bella será, pues, una forma que se explique a sí misma» (1990, 27). La libertad en la apariencia sería, pues, el fundamento de la belleza, pero la técnica constituiría, a su vez, la condición necesaria de nuestra representación aparente de su libertad $(1990,49)$. Un producto natural sería entonces bello si apareciera libre en su conformidad con el arte, mientras que un producto artístico gustaría si representara con libertad un producto natural $(1990,89)$.

La libertad en la apariencia, aunque sólo apariencia de libertad, con la que Schiller definió en Kallias la belleza, no significaba, por tanto, otra cosa que la autodeterminación de un objeto en su manifestación intuitiva. Un objeto dejaría de aparecérsenos libre, decía Schiller, tan pronto como descubriéramos el principio determinante - físico o inteligible — de su forma, lo que nos conduciría a pensar que su determinación no se hallaría en él, sino fuera de él, y que por esa heteronomía habría de carecer de belleza $(1990,23)$.

\section{De la estética analítica a la estética política. Lo bello en las Cartas sobre la educación estética del hombre}

En lo que respecta a las Cartas sobre la educación estética del hombre, la reflexión schilleriana sobre la belleza adquiere connotaciones distintas. La influencia de los acontecimientos históricos que se suceden tras la Revolución Francesa obliga a Schiller a desplazar su interés de lo que se ha considerado una aséptica analítica de la belleza, característica de Kallias, a sus efectos y función sociales, lo que escora su planteamiento hacia una estética política (Oncina y Ramos 2006, 196). En concreto, se trata de destronar al gran ídolo del presente, la utilidad o el provecho, y de hacer del hombre un ser íntegro y no escindido restableciendo en él la armonía de sus tendencias naturales contrarias, la sensible y la intelectual, sepa-

\footnotetext{
${ }^{5}$ La importancia de las reglas en la búsqueda de la belleza remite a las estéticas cartesianas, como la de Boileau, que convierte la justez̧a de la expresión en el concepto central (Cassirer 1997, $315)$.
} 
radas drásticamente por un Estado que sólo mira su interés y por una cultura excesivamente teórica que ha arrinconado la sensibilidad del hombre.

La intención de Schiller es también la de Fichte, quien, un año antes, había pronunciado sus Lecciones sobre el destino del sabio, en las que denunciaba igualmente la decadencia de su época y la necesidad imperante de regenerar la moral. Aun compartiendo el mismo diagnóstico, Schiller no admite los medios que propone el autor de la Doctrina de la Ciencia y que pasan por que el Yo empírico realice y dé forma al Yo puro (Rivera 2010, 38) ${ }^{6}$. No lo admite porque esa solución, como el desenlace de la filosofía kantiana, requiere la separación de forma y materia, lo que significa subordinar de nuevo los derechos de la sensibilidad a los de la razón. En consecuencia, Schiller opone a la educación fichteana e ilustrada del hombre, la cultura estética y artística, en la que las facultades humanas no entran en conflicto. ${ }^{7}$

Así pues, para entender la definición de la belleza que se nos propone en las Cartas, hay que tener en cuenta el contexto en el que se escriben, la Revolución francesa, y, a la par, la difícil relación que el pensador mantuvo con ella. Como ya se ha dicho, hacia 1790, Schiller aún tenía fe en la aplicación política del imperativo moral kantiano, en la capacidad de las instituciones políticas y del orden burgués de encarnar la racionalidad moral, y en la posibilidad de practicar una política y una moral asentadas sobre los principios de libertad, independencia e igualdad civil de los ciudadanos. Sin embargo, en 1793, tal y como lo atestiguan las Cartas al Príncipe F. C. von Schleswig-Holstein-Sonderburg-Augustenburg, se produce un cambio importante en el optimismo revolucionario de Schiller (Rivera

\footnotetext{
${ }^{6}$ Para Fichte, es el erudito (o el filósofo) quien ha de encargarse de llevar a cabo esa educación hacia la moralidad, que se logra principalmente a través de una cierta disciplina para el conocimiento.

${ }^{7}$ Los gérmenes de esta función mediadora de lo estético ya estaban presentes en un ensayo temprano de Schiller titulado El teatro considerado como institución moral (1784) y también en el poema Los artistas (1788-1789). En el primero se postula, como una exigencia de nuestra naturaleza, un estado (Zustand) intermedio que una los dos extremos, los sentidos y la razón, que modere su tensión y facilite la transición del uno al otro. Por su parte, en el poema Los artistas, se insinúa que la evolución cultural no comenzó con la razón, sino con el sentido estético; que es el sentido de la belleza el que ha domesticado y ennoblecido moralmente al hombre y el que ha dirigido la curiosidad característica del ser humano. Como señala Rüdiger Safranski, el poema no mira atrás elegiacamente, sino que incita a la modernidad a superar su olvido de sí misma a través de la dimensión estética (Safranski 2006, 287).
} 
2010, 36). No deja de ser irónico que, pese a su decepción con el curso de los acontecimientos, el dramaturgo terminara siendo nombrado ciudadano de honor de la República francesa y que se interpretara su exaltación de la libertad como una llamada o un apoyo a la Revolución (García 2000, 304). A partir de ese año, lo que ocurrió, sin embargo, fue que Schiller dejó de creer en la posibilidad de construir moralmente un mundo con medios exclusivamente políticos y/o racionales, lo que tornó su confianza inicial en un pesimismo desencantado (Rivera 2010, 47). Schiller ya no abrigaba ninguna esperanza en que la razón, puramente teórica, y la política, puramente prática, fueran capaces de realizar de facto el ideal moral, pues lo que comenzaba a pensar era, más bien, que ambas se inclinaban temerariamente hacia el dogmatismo del Antiguo Régimen, lo que se veía favorecido por el advenimiento de una razón instrumental que actuaba «al servicio del mal». Precisamente, la belleza sería propuesta por Schiller como sustituta de la razón en el papel de liderar una verdadera transformación política y social que devolviera al hombre la esperanza.

A la crítica a la Revolución dedicó Schiller las primeras nueve cartas. En ellas se percibe la influencia de Rousseau, si bien, el escritor alemán modificó el significado de la expresión «estado de naturaleza». La hipótesis roussouniana le sirvió para describir, no tanto el grado cero del derecho previo a la constitución pactada de la sociedad, cuanto el estado actual derivado de la Revolución, un - en su opinión- regresivo estado de naturaleza o, podríamos decir, de salvajismo, en el que la razón se convirtió en su contraria y en el que el hombre europeo inauguró el período de la «barbarie y la servidumbre». «Salvaje» y «apático» son dos de los epítetos que Schiller dirige al decadente hombre de su tiempo (1990, 137), lo que le conduce a abstraer la que conformará su conocida tesis acerca de la escisión del ser humano auspiciada por los excesos de la época: el hombre, por un lado, se convierte en un mero hijo de la naturaleza, que, al sobreexcederse, raya la locura y el frenesí; por otro lado, el hombre se vuelve un hijo de la cultura, que se corrompe igualmente por su confianza ciega en los supuestos poderes de la razón. ${ }^{8}$ En contraste con este paisaje y bajo la influencia de Winckelmann, Goethe y Humboldt, Schiller propone como ideal la civilización griega, en la que fantasía y razón logran aunarse y hacen, cada una a su manera, el mismo honor a la verdad.

\footnotetext{
${ }^{8}$ De los que Schiller, claramente, desconfía: «La ilustración de la que se vanaglorian, no del todo sin razón, las clases más refinadas, tiene en general un influjo tan poco beneficioso para el carácter, que no hace sino asegurar la corrupción valiéndose de preceptos» $(1990,139)$.
} 
La diferencia entre el hombre griego y el hombre moderno es para Schiller clara: «al primero le dio forma la naturaleza, que todo lo une, y al segundo el entendimiento, que todo lo divide» $(1990,149)$. Llegamos a ser hombres fragmentados cuando el avance científico hizo necesaria la parcelación de las ciencias, y cuando la sofisticación y complejidad de los estados modernos requirió, a su vez, la separación de los estamentos sociales y la instauración de la división del trabajo. Como consecuencia de su desapego del hombre, el propio estado se desalmó, convirtiéndose en la «objetividad por antonomasia» (1990, 149) o, en metáfora de Schiller, en un «artificioso mecanismo de relojería» en el que «la existencia mecánica del todo se forma a partir de la concatenación de un número infinito de partes que carecen de vida propia» $(1990,149)$. Fue así como se disociaron el estado y la iglesia, las leyes y las costumbres, el placer y el trabajo, el medio y la finalidad, y el esfuerzo y la recompensa. El hombre, transformado en una parte más, exánime y autómata, del mecanismo estatal, comenzó entonces su proceso paralelo de disminución. La consecuencia es estremecedora: «ligado eternamente a un único y minúsculo fragmento del todo, el hombre mismo evoluciona sólo como fragmento» $(1990,149)$. Para escapar de esta situación, Schiller propone una cultura más elevada que reestablezca la unidad desperdiciada del hombre. El ennoblecimiento del estado pasa así por la educación, en cada uno de sus miembros, de la facultad sensible y emocional.

\section{El impulso de juego y la lebende Gestalt}

El propósito de las Cartas es, pues, superar el hiato de la filosofía kantiana y de la práctica política revolucionaria que separa sensibilidad y razón o necesidad y libertad para lograr una plenitud en el seno mismo del hombre que pueda repercutir positivamente en la vida social. Para ello, Schiller va a «humanizar» la dicotomía kantiana transformándola, bajo la influencia de Reinhold y Fichte, en sendos impulsos (Trieb) humanos, el sensible y el formal'.

\footnotetext{
${ }^{9}$ La mediación estética no es deducida de las facultades humanas en abstracto, sino de los impulsos. Este carácter impulsivo, instintual, de lo estético lo acerca a una teoría de las necesidades humanas como exigencias de nuestra naturaleza. No por casualidad, estos factores pulsionales embrionarios, auxiliados por el magisterio de Freud, dieron después pie a Marcuse para elaborar su teoría de la dimensión estética (Marchán 1996, 73-74).
} 
Recordemos brevemente que el impulso sensible, también llamado «impulso de cosa» o «impulso objetivo», depende de la existencia material del hombre y se ocupa de situarlo en los límites del tiempo. Según Schiller, este impulso requiere variación y que el tiempo tenga contenido. Con él, se manifiesta la existencia física o sensible del ser humano. El hombre no es, en este estado, más que un momento lleno de contenido, o, más bien, no es él, porque su personalidad desaparece mientras le dominan las sensaciones y el tiempo le devasta. Por eso, cabe decir que, si bien el impulso sensible es capaz de despertar las demás disposiciones humanas, también es el único que imposibilita la perfección de la humanidad. Por su parte, el impulso formal depende de la naturaleza racional del hombre y se encarga de proporcionarle libertad, de armonizar la multiplicidad de sus manifestaciones y de afirmar su persona frente a todos los cambios temporales de estado. Como dice Schiller gráficamente, el impulso formal «decide para siempre lo que decide ahora y exige ahora lo que exigirá para siempre». Abarca, pues, todo el tiempo, o, lo que es lo mismo, «lo suprime» (1990, 197). Si el impulso sensible despierta con la experiencia de la vida, el racional lo hace con la experiencia de la ley, y sólo con su irrupción es posible construir fehacientemente la humanidad del hombre.

Bajo esta dicotomía subyace la tesis de que el hombre es, por un lado, algo que permanece — la persona — , y, por otro, algo que cambia —el estado—. El ideal schilleriano del hombre viene representado por su parte invariable y permanente, que se afirma por encima de las transformaciones arbitrarias de su estado: «El hombre, representado en su perfección, sería, por consiguiente, aquella unidad persistente que, en el flujo de las variaciones sigue siendo siempre la misma» $(1990,197)$. A ese estado ideal lo llama Schiller «divinidad»y, según dice, es propio del hombre tender hacia ella. Para que el hombre dominado por el impulso sensible la alcance, ha de dar forma a la materia; pero, a su vez, el hombre tiranizado por el impulso formal tiene también que dar realidad — materializar- esa su disposición.

En aras de su acercamiento progresivo a lo divino, los impulsos sensible y formal han de limitarse entre sí y mantener una relación recíproca (Wechselwirkung) de carácter dialéctico, de la que surja, a su vez, un tercer impulso —el de juego- que suprima y conserve los dos (que practique una Aufhebung). La postulación de este impulso intermediario, cuyo núcleo es la belleza, es, en el caso de Schiller, una exigencia de la razón: «Así pues, en cuanto la razón proclama que 
ha de existir una humanidad, formula al mismo tiempo la ley de que ha de existir una belleza» $(1990,233)$. Schiller está convencido de que esto no se ha planteado hasta ahora, aunque, sin duda, las referencias al aspecto lúdico de la experiencia estética pueden vislumbrarse de nuevo en la filososofía de Kant, en concreto, en el libre juego de las facultades que se pone en práctica en los juicios de gusto.

El impulso de juego es así el que permite que la persona, que es libre y se autofundamenta, se concilie con el transcurso temporal, que modifica sus determinaciones o estados. El impulso de juego lo faculta porque es el único que congrega sin anularlas las características contrapuestas de los otros dos impulsos. En concreto, es capaz de «suprimir el tiempo en el tiempo, unir el devenir con el ser absoluto, la variación con la identidad» $(1990,197)$. Por eso, el impulso de juego constituye el símbolo del cumplimiento de la determinación humana. En opinión de Schiller, sólo la belleza, o el juego, como forma viva (lebende Gestalt) ${ }^{10}$, neutraliza la doble constricción física y moral.

Que la belleza sea «forma viva» quiere decir que, como «forma», es un objeto para nosotros, pero que, como «vida», es un estado de nuestro sujeto: «La belleza es, pues, forma, porque la contemplamos, pero es a la vez vida, porque la sentimos» $(1990,339)$. Con la belleza aprendemos, en suma, que la necesaria dependencia física del hombre no constriñe su libertad moral. Con la belleza entramos, pues, en el territorio de la autonomía humana, porque el estado estético equilibra los dos platillos de la balanza suprimiendo y conservando las determinaciones sensible y racional $(1990,283)$. Contrapuestas ambas, el hombre alcanza un estado de determinabilidad absoluta en el que la ausencia de determinaciones indica que aún no es, pero en el que la ausencia de constricción le anuncia también que sus posibilidades de ser son ilimitadas:

Lo único que consigue la cultura estética es que el hombre, por naturaleza, pueda hacer de sí mismo lo que quiera, devolviéndole así por completo

\footnotetext{
${ }^{10}$ Para Aullón de Haro, Schiller es quien realiza abiertamente la gran operación neoplatónica, esto es, la forma en tanto que síntesis dialéctica de los impulsos resuelta en figura viva (lebende Gestalt). En este sentido, recupera la belleza renacentista de Marsilio Ficino y la antigua de Plotino, el fundador neoplatónico de esta concepción, para quien la belleza no era sino el alma o su huella reconocible en los cuerpos, es decir, relativa a la esencia (Oncina y Ramos 2006, 119).
} 
la libertad de ser lo que ha de ser. Pero con ello se consigue algo infinito: tan pronto recordemos que precisamente esa libertad le fue arrebatada en el estado sensible por la coacción unilateral de la naturaleza, y en el pensamiento por la legislación exclusiva de la razón, tenemos que considerar entonces a la facultad que se le devuelve al hombre en la disposición estética como el don supremo, como el don de la humanidad $(1990,283)^{11}$.

La belleza regala al hombre la experiencia de su cumplida humanidad y, por tanto, como dice Schiller, «el hombre sólo es enteramente hombre cuando juega» $(1990,233)$.

Dado que la acción recíproca de los dos impulsos sólo es un ideal, la cultura debe promover al menos su desarrollo paulatino asegurando una educación estética del hombre. Schiller tiene muy claro que el verdadero Estado tiene que ser, como la belleza, una forma política que esté viva en los corazones de los ciudadanos y que éstos deben a su vez ennoblecer su carácter enriqueciendo su facultad racional con una Bildung estética. Un estado moral perfecto sólo será real entre hombres que depuren su sensibilidad y su racionalidad hasta el punto de confiar su moralidad a sus impulsos, de convertir su obra moral en naturaleza (García 2000, 303) ${ }^{12}$. En otras palabras, entre hombres que alcancen la gracia y la dignidad.

${ }^{11} \mathrm{Al}$ caracterizar el estado estético como aquella disposición del ánimo en la que se carece de toda determinación, Schiller sólo está poniendo énfasis en la idea de una experiencia de nuestra propia humanidad — de un autoconocimiento, diría Gadamer — en la que queda abierto a cada quien dar contenidos específicos a sus impulsos (Rivera 2010, 66).

${ }^{12}$ Se ha puesto ya de manifiesto que una de las preguntas que suscita la propuesta de Schiller atañe a cómo logra establecer, sin caer en contradicción con sus presupuestos, el paso de una experiencia momentánea de la libertad estética, enmarcada en los efectos que pueda tener el arte en el espectador, a ese hacer al hombre libre efectivamente y de hecho en el que consiste la seriedad última detrás de la aparente trivialidad propia del placer estético. Para María del Rosario Acosta, la respuesta está ligada tanto a la manera como Schiller define en las Cartas la noción de libertad estética —en el sentido de un carácter adquirido progresivamente, como complemento y alternativa al carácter puramente moral kantiano-, como a la interpretación que se ofrece de la noción de educación, muy en la línea clásica del hábito como camino a la disposición. Así, la experiencia estética debe despertar en el ánimo una disposición, una manera de ser propia de la naturaleza sensible-racional del hombre o un carácter que, una vez cultivado, incida y haga posibles las manifestaciones particulares de éste en la acción (Rivera 2010, 63-64). 


\section{La gracia y la dignidad}

La reflexión en torno a la armonía de lo sensible y lo intelectual desde el punto de vista del individuo se completa en los ensayos que Schiller consagró a la gracia y la dignidad. El texto de homónimo título apareció por primera vez en la revista Neue Thalía (3, pieza $2^{2}$ ) en 1793. El editor de la revista (continuación de la Rheinische Thalia, fundada en 1785 en Mannheim, y de la Thalia, que empezó a salir, a partir de 1786, en Leipzig), era el propio Schiller y el motivo de su redacción, la falta de contribuciones para esta nueva publicación. Safranski dice que el ensayo fue redactado en seis semanas, entre febrero y mayo de 1793, con el paréntesis impuesto por la enfermedad pulmonar que aquejaba a Schiller desde hacía años $(2006,367)$.

En Sobre la gracia y la dignidad, Schiller define la gracia (Anmut) como una belleza en movimiento, que puede surgir y cesar casualmente en un sujeto. Precisamente en eso se distingue de la belleza permanente, de construcción o arquitectónica que, viene dada desde su origen con el sujeto $(1985,10)$. El carácter intermitente o temporal de la gracia indica que ésta sale a relucir en los movimientos voluntarios, y, especialmente, en los que son expresión de sentimientos morales, aunque también, según dice Schiller, en lo que de indeliberado puede haber en lo deliberado:

Si la gracia es, pues, una cualidad que exigimos de los movimientos voluntarios, y, por otra parte, hay que desterrar de la gracia misma todo lo voluntario, tendremos que buscarla en aquello que en los movimientos deliberados no es deliberado, pero que al mismo tiempo corresponde a una causa moral en el ánimo $(1985,29)$.

De ahí que la gracia sea «una belleza no dada por la naturaleza sino producida por el espíritu mismo» $(1985,13)$, que se corresponde con la aparición sensible de la libertad humana. Por eso Schiller la define también como «la belleza de la forma bajo la influencia de la libertad» $(1985,22)$. En la gracia, el principio de autodeterminación sustituye a la naturaleza y eso convierte al hombre en virtuoso. 
Es más que evidente que, con esta definición ético-estética de la virtud, se promueve un alejamiento de la moral kantiana, en la que la idea del deber se presenta, como afirma Schiller, con una dureza tal, que «ahuyenta a las Gracias»y hasta "podría tentar fácilmente a un sentimiento débil a buscar la perfección moral por el camino de un tenebroso y monacal ascetismo» $(1985,42)$. En contraposición, Schiller asegura que un alma es bella cuando el sentido moral puede abandonar la dirección de su voluntad al afecto sin correr el riesgo de contradecir sus decisiones. Es, pues, en el alma bella donde armonizan sensibilidad y razón, inclinación y deber, y la gracia es su expresión en lo fenoménico (1985, 45). El alma bella encarna así la recuperación de la espontaneidad en el obrar, el retorno de la moralidad a la naturaleza en el marco de un comportamiento excelsamente humano.

Los guiños de este ensayo a las Cartas sobre la educación estética del hombre y a Kallias son más que evidentes. En el segundo de estos libros se afirma también que la belleza moral constituye el grado máximo de perfección del carácter humano, y que sólo se presenta cuando el deber pasa a formar parte de la naturaleza (1990, 39). Una acción moral sólo es bella si parece un efecto natural. En otras palabras: «una acción libre es una acción bella cuando coinciden la autonomía del ánimo y la autonomía en la apariencia» $(1990,39)$. Por eso, es normal que prefiramos las acciones meramente emotivas a las puramente morales. Las primeras, en opinión de Schiller, son realizadas voluntariamente y por obra de la naturaleza (la emoción), no a partir de la razón, que se impone en contra del interés de lo sensible. En las Cartas, por su parte, se afirma también que, para considerar el comportamiento moral del hombre como una consecuencia natural, es necesario que ese comportamiento sea natural, y que el hombre sea inducido por sus propios impulsos a obrar moralmente $(1990,129)$.

Si la gracia es la expresión de un alma bella, la dignidad lo es de un carácter sublime $(1985,47)$. La dignidad se manifiesta cuando la naturaleza es sometida al espíritu $(1985,55)$. De ahí que, a diferencia de la gracia, que sobresale en la conducta, la dignidad se exija en el padecer. De ello, Schiller extrae incluso una especie de ley: «el hombre debe hacer con gracia todo lo que puede llevar a cabo dentro de su humanidad, y con dignidad todo aquello para cuya ejecución debe trascender su humanidad» $(1985,56)$. La gracia y la dignidad pertenecen a dominios distintos, pero, precisamente por eso, no se excluyen entre sí; es más, según afirma Schiller, sólo de la gracia recibe la dignidad sus credenciales, y sólo la digni- 
dad confiere a la gracia su valor $(1985,58)$. Si ambas se encuentran en una misma persona, en ella es perfecta la expresión de la humanidad. Pero, ¿que entiende Schiller por sublime?

\section{El concepto de lo sublime}

Comencemos examinando una de sus definiciones de este concepto:

Llamamos sublime al objeto cuya representación pone de manifiesto los límites de nuestra condición sensible y, a la par, la superioridad de nuestra naturaleza racional, y su independencia de toda constricción. Así pues podemos elevarnos moralmente - es decir, mediante las ideas - sobre lo que físicamente nos coloca en situación de inferioridad. Sólo somos dependientes como seres sensibles. En cambio, como seres racionales somos libres $(1992,73)$.

Según esta definición, lo sublime provoca un doble efecto: nos hace sentir nuestra dependencia como seres sensibles, por un lado; y nos revela la independencia del ser racional, por otro. Schiller añade que, para tener conciencia de nuestra autonomía, es preciso representarse la naturaleza en pugna con nuestras necesidades, o, más en concreto, con el instinto, ya sea el representativo o cognoscitivo, que nos mueve a cambiar la situación en que nos encontramos; ya sea el de autoconservación, que nos impulsa a conservar nuestro estado actual y que implica el sentimiento. Los dos entrañan dependencia de la naturaleza, bien porque la naturaleza carece, en el primer caso, de las condiciones para ser conocida; bien porque, en el segundo, se halla en pugna con las exigencias de nuestra supervivencia $^{13}$.

Para Schiller, la razón nos permite afirmar una doble independencia respecto a la naturaleza: nos capacita, por un lado, para traspasar en el ámbito teórico las condiciones naturales y pensar más de lo que podemos conocer; y, por otro, nos permite desatender las exigencias de la naturaleza y oponernos con

\footnotetext{
${ }^{13}$ «Como objeto de conocimiento, la naturaleza se halla en el dominio de lo sublime teórico en contradicción con el instinto de representación. Como objeto de la sensibilidad se encuentra, dentro del ámbito de lo sublime práctico, en oposición con el instinto de conservación» (Schiller 1992, 74).
} 
la voluntad a los deseos. Aquello que proporciona lo primero es teóricamente grande y activa lo que Schiller llama «sublime de conocimiento»; aquello que proporciona lo segundo es, por su parte, prácticamente grande e impulsa lo «sublime de carácter».

Es más que evidente que esta tipificación procede también de la de Kant, quien, en la Crítica del juicio, había diferenciado lo sublime matemático de lo sublime dinámico para indicar cómo, en el primer caso, el ánimo era referido, mediante la imaginación, a la facultad cognoscitiva, mientras que en el segundo lo era a la facultad apetitiva. Como afirmaba Kant en relación al primero, en él, todo sucedía como si la imaginación se enfrentara a su propio límite cognoscitivo, como si sufriera una violencia que la llevara al extremo de su poder. Gilles Deleuze lo ha explicado de la siguiente manera: «Sin duda, en la medida en que se trata de aprehender (aprehensión sucesiva de las partes), la imaginación no tiene límite. Pero cuando se trata de reproducir las partes precedentes a medida que llega a las siguientes, tiene un máximo de comprensión simultánea» $(1997,92)$. Ante lo inmenso, la imaginación experimenta la insuficiencia de este máximo. A primera vista atribuimos a la naturaleza sensible esa inmensidad que reduce nuestra imaginación a la impotencia. «Pero en verdad — prosigue Deleuze_-, nada, fuera de la razón, nos fuerza a reunir en un todo la inmensidad del mundo sensible. Así se percata la imaginación de que es la razón la que, al impulsarla al límite de su poder, la fuerza a confesar que toda su potencia no es nada en comparación con una Idea» $(1997,92)$. Lo sublime matemático surge así de la imposibilidad de la imaginación de aprehender sensible y sucesivamente las partes de que consta el inmenso objeto de representación, y de la necesidad consecuente de que la razón participe proponiendo una superación de la experiencia y postulando la idea de infinito. La idea de infinito es, pues, concebida sin que quepa imaginarla o pensarla, y justamente, esa liberación de las limitaciones de la experiencia provoca en el hombre el sentimiento contradictorio - doloroso y placentero- de lo sublime. Sentimos entonces nuestra pequeñez y al mismo tiempo nuestra grandeza.

La pertenencia de lo sublime matemático a la esfera de lo propiamente cognoscitivo tiene, en el caso de Kant, la consecuencia de que representa el modelo originario y más puro de lo sublime (Oncina y Ramos 2006, 98). Schiller, en cambio, se decanta por lo sublime práctico (dinámico), que se contrapone, no a la facultad de conocer, sino a nuestra existencia (voluntad), afectando directa- 
mente a la libertad y, con ella, a la constitución moral del ser humano ${ }^{14}$. Hay que tener en cuenta, para entender este interés particular de Schiller, que esta otra modalidad, a diferencia de la que afecta a lo sublime de conocimiento, posee mayores posibilidades de desarrollo estético. No por otra razón, tanto en De lo sublime como en Sobre lo patético, lo sublime práctico es considerado, en una nueva superación de la filosofía kantiana, como el fundamento artístico de la tragedia (Oncina y Ramos 2006, 98).

Schiller defiende que, en la tragedia, el lado negativo de la existencia se presenta como una necesidad o «destino» que se opone al principio de autodeterminación individual. En la imposibilidad de oponerse existencialmente a lo espantoso, surge la posibilidad de resistirse moralmente a la violencia que ejerce sobre nosotros. Esta resistencia moral es la que convierte lo terrible en sublime y la que revela, al mismo tiempo, la pertenencia del hombre al universo a un tiempo físico y moral. El fin de la tragedia es, pues, que el pathos visibilice la naturaleza noble del hombre, y que éste consiga en lo sublime afirmar su voluntad sobre la sumisión a lo necesario.

Para Schiller, esta autonomía del espíritu frente a lo patético puede revelarse de dos maneras: la primera, llamada «sublime de templanza», surge cuando el estado de negatividad no es elegido libremente por el hombre y, por tanto, ante la fatalidad exterior, se limita a afirmar su autonomía. La segunda, llamada «sublime de acción», presupone un sufrimiento causado deliberadamente por el hombre al coaccionar, como ser moral, las exigencias o caprichos de su ser físico. En

\footnotetext{
${ }^{14}$ Esta modalidad sirve también para lo sublime de la experiencia religiosa: «Para que la idea de divinidad se torne práctica, dinámicamente sublime, es preciso buscar el sentimiento de seguridad en nuestros principios fundamentales no en la existencia. Si como inteligencias nos sentimos independientes de los efectos de su poder, debe resultarnos indiferente lo que nos sucede como seres naturales. Únicamente cuando no puede aniquilar nuestra autonomía ni es capaz de forzar a la voluntad a obrar en contra de sus principios, nos percibimos independientes como seres racionales de su omnipotencia. Así pues, la idea del poder de la divinidad es dinámicamente sublime cuando le negamos cualquier posibilidad de influir de modo natural sobre las decisiones de la voluntad» (Schiller 1992, 85-87). Y también: «Así pues, en el único caso en que la Divinidad podría convertirse en una realidad terrible, aquél en que recibimos su reprobación, no dependemos de ella. Representada como poder capaz de abolir nuestra existencia — aunque sin posibilidad de influir sobre las acciones de la razón mientras la conservamos-, la Divinidad es dinámicamente sublime. Por consiguiente, sólo la religión que brinde esa idea de la Divinidad lleva en sí el sello de lo sublime» $(1992,87)$.
} 
este segundo caso, el estado de negatividad es, pues, consecuencia de una actividad humana libremente elegida $(2004,16)$. Lo sublime patético exige, en ambos casos, dos condiciones que conforman, para Schiller, las leyes fundamentales del arte de la tragedia: la representación viva del sufrimiento y la resistencia al dolor. El sufrimiento, que nos conmueve en tanto seres sensibles, sólo se justifica estéticamente a través de la afirmación de la persona como ser libre. No se trata de recrearse en el dolor, sino de que el sufrimiento del héroe, para que sea verdaderamente trágico, sea apaciguado por su superioridad moral (Oncina y Ramos 2006, 105-106). De ahí que Schiller establezca que lo patético sólo es estético en tanto en cuanto es sublime.

\section{Conclusión. Hacia una síntesis categorial de lo bello y lo sublime}

El concepto de lo sublime se formula, en la estética de Schiller y en similitud con su noción de la belleza, en relación con lo suprasensible, en concreto, con la tendencia a la divinidad que, como ideal, caracteriza al ser humano, y que, según las Cartas sobre la educación estética del hombre, requiere el ennoblecimiento previo de la sensibilidad. Es más, sólo la sensibilidad abre paso al cumplimiento efectivo de la determinación humana en su acercamiento tentativo a la determinación divina. El impulso de juego, igual que la sublimidad del hombre, garantiza, en Schiller, el logro de esa determinabilidad plenamente humana que afirma rotunda su libertad. Desde este punto de vista, lo sublime puede entenderse como una extensión de la educación estética del hombre o como el último paso de esa Bildung integral, superadora de la ilustrada, en la que la belleza ocupa un puesto tan importante. Lo sublime sería, desde esta perspectiva, el extremo o la manifestación culminante de los logros de la formación estética del hombre.

Belleza y sublimidad se hermanan, en la obra de Schiller, en tanto en cuanto los une el principio de autodeterminación de la voluntad. La educación en la belleza es propuesta, justamente, porque enseña al hombre lo que significa ser libre, porque el impulso de juego suprime las determinaciones sensibles y racionales y abre un espacio ficticio de determinabilidad infinita en el que, cual escenario en que los actores dejan de ser y se convierten en otros, el hombre anula sus coerciones y se emancipa. Gracias a la belleza, tomamos conciencia de nosotros en tanto seres libres e indeterminados, infinitos en nuestra finitud, y, por tanto, 
la belleza, como anticipación de lo infinito en el hombre, proclama nuestra sublimidad. Por decirlo de otra manera, lo sublime se apr(eh)ende a través de la belleza, o la belleza, como aprendizaje de la autodeterminación, nos encamina hacia la sublimidad. Se requiere de nosotros sublimidad tan sólo en aquellas situaciones en que resulta imposible la gracia, o sea, la armonía espontánea de la inclinación y el deber, situaciones que, no por minoritarias, resultan menos importantes. Si el «alma bella» es la expresión fenoménica de nuestra libertad, el «alma sublime» no es más que la expresión fenoménica de nuestra afirmación como seres bellos, es decir, libres y racionales, o sea, sublimes. Pero no se puede alcanzar la dignidad sin haber conquistado antes la gracia. La «serenidad en el padecer», con la que se define el hombre digno, no constituye sino la manifestación sublime de su belleza moral, la victoria de la razón sobre la rebeldía del instinto, su domesticación y apaciguamiento - de nuevo, pues, el restablecimiento de su armonización graciosa - que se sigue de un estado previo de conmoción; de ahí su grandeza, pero también —o lo que es lo mismo— su doble hermosura, es decir, su belleza... sublime.

No se trata de educar primero en la belleza y después en la sublimidad, sino de que en la primera está incuida ya, en potencia, la segunda. Es cierto que la belleza educa armonizando el impulso sensible y el impulso formal, y la sublimidad lo hace aminorando la furia de la naturaleza. Pero ambas persiguen la misma finalidad, la afirmación de la autodeterminación humana (García 2000, 378).

Desde el punto de vista de las facultades que se activan en la experiencia de lo bello y lo sublime, en el caso de Schiller, podemos decir que no revelan diferencias sustanciales. No hay en su caso, como en Kant, la necesidad de separar los movimientos o inclinaciones de la conciencia en función de que la experiencia estética derive de lo bello o de lo sublime. En ambos casos, la facultad imperante es, en Schiller, la racional, la voluntad autodeterminadora del ser humano. En lo bello, esa voluntad se presenta en perfecta armonía con los sentidos, y lo mismo ocurre en lo sublime, sólo que aquí la serenidad en el padecer pasa por el control previo del desorden sensible. Pero el resultado final es similar al del alma bella: en ambos casos, razón e instinto se armonizan, lo que significa que el alma sublime es, al mismo tiempo, un alma bella.

Cuando Winckelmann definió la belleza como «la noble sencillez y la serena grandeza» $(1987,36)$, estaba formulando ya una síntesis categorial muy simi- 
lar a la que ocultan los textos de Schiller. En esa fórmula quedaban reunidas armónicamente las ideas de lo sublime (serenidad y grandeza) y de la gracia (nobleza y sencillez). Con el clasicismo como modelo, en la noción winckelmmaniana de la belleza, se unían sin contradicción las categorías estéticas que Kant separaba, y se establecía, al mismo tiempo, la definición, tal vez más importante e imperecedera, del clasicismo artístico. El ideal de belleza se expresaba así en una serenidad anímica manifestada corporalmente, que lograba reflejar la nobleza y la grandeza del carácter. Para Winckelmann, como también para Schiller, ésa había sido la gran enseñanza de los griegos, quienes como portadores de un ethos aún no escindido, eran capaces de manifestar artísticamente su carácter noble y sereno, bello y sublime al mismo tiempo $(1987,11)$. Incluso en los momentos de dolor, se evitaba perder la compostura. El famoso grupo escultórico del Laocconte, en comparación con el tremebundo de Virgilio - cuyos gritos de espanto resuenan en las páginas silencionsas de la Eneida-, expresaba perfectamente esa belleza sublime que compensaba con elegancia la violencia del dolor con la manifestación de la serenidad del alma (1987, 36-37). Para esa obra de arte vale también la definición de Schiller de belleza como libertad en la apariencia, como expresión sensible de la libertad y/o superioridad moral del protagonista que sufre; pero a esa escultura también le vale la noción schilleriana de lo sublime patético como conjunción entre sufrimiento y resistencia moral. El Lacoonte, según esto, estaría dotado, a un tiempo, de gracia y de dignidad, y constituiría, por tanto, un inmejorable ejemplo de lo que podemos llamar, sin riesgo ya de confundirnos, una sublime belleza.

\section{BIBLIOGRAFÍA}

CAssirer, E. (1997). Filosofía de la Ilustración, México: FCE.

Deleuze, G. (1997). La filosofía crítica de Kant, Madrid: Cátedra.

García García, J. (2000). A la libertad por la belleza: la propuesta filosófica de Friedrich Schiller, Madrid: UNED Ediciones.

Kant, I. (1999). Crítica del juicio, Madrid: Espasa-Calpe.

Marchán Fiz, S. (1996). La estética en la cultura moderna, Madrid: Alianza.

Molinuevo, J. L. (1998). La experiencia estética moderna, Madrid: Themata, Síntesis. 
Oncina, F. y Ramos, M. (eds.) (2006). Ilustración y modernidad en Friedrich Schiller en el bicentenario de su muerte, Madrid: UV.

Rivera García, A. (ed.) (2010). Schiller, arte y política, Murcia: Edit.um.

Rorty, R (2001). «La belleza racional, lo sublime no discursivo y la comunidad de filósofas y filósofos», Logos. Anales del Seminario de Metafísica, 3, 45-65.

SAFrANSKi, R. (2006). Schiller o La invención del idealismo alemán, Barcelona: Tusquets.

SAint Girons, B. (2008). Lo sublime, Madrid: Visor.

SCHILLER, F. (1985). Sobre la gracia y la dignidad. Sobre poesía ingenua y poesía sentimental y una polémica: Kant, Schiller, Goethe y Hegel, Barcelona: Icaria.

- (1990). Kallias. Cartas sobre la educación estética del hombre, Barcelona: Anthropos.

- (1992). Lo sublime. (De lo sublime y Sobre lo sublime), Madrid: Ágora.

- (2004). Escritos breves sobre Estética, Sevilla: Doble.

WincKelmann, J. J. (1987). Reflexiones sobre la imitación del arte griego en la pintura y la escultura, Barcelona: Nexos.

Recibido: 6/12/2012

Aceptado: 12/04/2012 